\title{
Breaching the Neonatal Intensive Care Unit: The Needs and Feasibility of in Hospital ESP Instruction
}

\author{
Daniel Rueckert \\ International Center for Intercultural Communication \\ Cavanaugh Hall 133, 425 University Blvd \\ Indianapolis, Indiana USA 46202 \\ Esen Gokpinar-Shelton \\ International Center for Intercultural Communication \\ Cavanaugh Hall 133, 425 University Blvd \\ Indianapolis, Indiana USA 46202
}

\begin{abstract}
:
Children born to Limited English Proficient (LEP) caregivers experience high risks of mortality and have difficulty obtaining specialty care. English and health literacy programs tailored to caregivers are rare. This study developed tailored English instruction to assist native Spanish speaking LEP caregivers to more fully integrate into their children's healthcare teams. We implemented a thorough needs assessment leading to a six-module tailored English intervention with five LEP caregivers. Pre/post analyses were conducted to measure effect of interventions on healthcare literacy, confidence, and integration into the healthcare team. All subjects showed improvement from pre to post tests of English language use and health literacy while qualitative data showed increases in confidence and integration into healthcare teams. In hospital, English language interventions can improve LEP caregiver participation in their children's healthcare team and improve language and health literacy skills, but feasibility concerns of providing these programs remain.
\end{abstract}

Keywords: ESP, NICU, Medical English, Caregiver

\subsection{Rationale}

Discharge from a Neonatal Intensive Care Unit (NICU) is a complicated, lengthy and stressful process for all parents involved (Craig, 2016 \& Sneath, 2009). The factors such as exposure to medical jargon and inadequate communication between healthcare providers and parents exacerbate parents' emotional conflicts and undermine their involvement in the process. While this can be a challenge for native English speaking families,for those from different cultures whose first language is not English and who have low health literacy skills, this barrier may seem insurmountable. Compared to English proficient parents, for example, Limited English Proficient (LEP) Latino parents with low health literacyhave been found more likely to identify their children's health as fair or poor, not seek medical care when needed, and be uninsured (Flores, Abreu, \& Tomany-Korman, 2005). These non-native English-speaking parents were also found to require greater effort on their part to enroll in services post-discharge from the NICU (Litt \& Perrin, 2014). Thus, the children of these parents have been more likely to be triaged to higher levels of acuity, to spend more time in the emergency room, and to have higher diagnostic costs (Betz,Ruccione, Meeske, Smith, \& Chang, 2008).

A body of research has established that ongoing access to information and communication with neonatal service providers are salient coping strategies to mitigate the complicated and stressful process for all families in the NICU as well as helping the parents increase their level of health literacy (Miles, Carlson, Funk, 1996; Seideman, Watson, Corf, Odle, Haase, Bowerman, 1997). LEP Latino parents confirmed the psychological benefits of their access to information and communication with neonatal service providers (Santarelli, Denney, Singer \& Singer, 2000; Lorant, 2012). However, linguistic and cultural barriers were found to increase the difficulties and stress of the NICU experience for these LEP parents as they frequently did not receive adequate information. This was attributed to few Spanish speaking health care professionals or translators being available in the NICU (Santarelli et al., 2000).

The recent definition of health literacyhas been expanded to include "the wide range of skills and competencies that people develop to seek out, comprehend, evaluate and use health information and concepts to make informed choices, reduce health risks and increase quality of life" (Zarcadoolas, Pleasant, \& Greer, 2005). This definition is in line with LEP parents' needs, pointing to a model of health literacy that considers more than fundamental literacy and numeracy, but also includes linguistic and cultural literacy. 
The Institute of Medicine has emphasized that health literacy cannot be separated from language and culture; low literacy, language barriers, and cultural diversity must all be considered to ensure effective health communication(2002).

While the changing definition of health literacy has been encouraging, a close search of the literature has suggested that there was no effective solution targeted to help LEP parents with low health literacy in NICU settings. Although existing health-related English language programs have been effective training adults about their own health on topics such as eating healthy, medicine adherence, emergencies, appointments, prevention, etc., these programs do not address the concerns of LEP low health literate caregivers regarding their preparation to care for their children at the point of discharge from the NICU (Miquel-Verges, Donohue, \& Boss, 2011, Singleton, 2004). Therefore, there was a clear need for the development of short-term English health-related language and cultural education programs to assist LEP parents in their efforts to integrate more fully with their children's healthcare teams with a focus on improved communications between team members. A 2012 survey among 38 Latino families with infants in an Indiana University Health NICU found that $94 \%$ were interested in taking healthcare-specific English classes at the hospital if they were offered such classes during their infants' hospitalization (Lorrant, 2012). The will of the LEP parents in the NICU with the documented need for language and health literacy instruction prior to hospital discharge illustrated the need for the study.

There were two outcomes from the study. The first was the development of a needs and evidence informed six-module English language education program designed to provide targeted health-related English language skills to Latino LEP caregivers whose first language is Spanish. Themodules designed to be used in hospital or community settings, locally and nationally.The second outcome was improvement in caregivers' health-related English and continued use of these skills after infant discharge.

\subsection{Theoretical Model}

Andrulis and Brach (2007) identify three training approaches commonly taken to address health disparities in LEP populations: Health literacy programs, cultural competence training, and language assistance programs. These programs, however, tend to teach the approaches in isolation. For example, health materials that are written in plain English do not take cultural considerations into account, and they may not be accessible to those with LEP (Andrulis \& Brach, 2007). The proposed study integrates all three approaches, health literacy, cultural competence, and language assistance to best meet the needs of low health literate, LEP, and culturally diverse patients- in this case, the LEP Latino families and caregivers of NICU and pediatric intensive care unit (PICU) infants. These three training approaches developed aroundtwo strong theories: English for Specific Purposes (ESP) and Intercultural Communication.

ESP theory stayed at the center of the intervention modules design, following guiding principles from Connor and Upton (2013). The study includedan extensive analysis of learner needs, direct use of materials,tools, equipment and resources that the learner would need to use after program completion; improvement of English language skills along with content knowledge related to heath literacy, and valid assessment using tailored assessments directly linked to the goals and outcomes. ESP was selected for its focus on practical, specific outcomes, as opposed to general English language education programs, which teach a broad range of language skills. An advantage of a focused ESP approach over general English is no wasted time. Learning is immediately relevant to the learner resulting in higher learner motivation (Dudley-Evans \& St. John, 1998). Programs such as this intervention address the needs of "language and literacy learners... who are especially disadvantaged by their lack of language needed for the situation they find themselves in, hope to enter, or eventually rise above" (Belcher, 2009, p.2).

In addition, the intervention modules took the component of intercultural communication competency as the point of departure for activities. Byram's well-developed model (1997) suggested that intercultural communicative competence requires awareness, knowledge, skills, and interaction in linguistic settings to become interculturally communicative as an individual. Byram's intercultural communicative competence model informed our intervention, which developed language and cultural competence through instruction and interaction.

\subsection{Methods}

The study was conducted as part of a one-year Community Health Engagement Program (CHEP) grant funded by the Indiana Clinical Translational Sciences Institute (CTSI), a statewide program administered by Indiana University. The CHEP program promotes the collaboration of academic research with community organizations around Indiana. For this project, the International Center for Intercultural Communication (ICIC) partnered with Family Voices Indiana (FVI), a community organization of parents of children with special needs that provides support services to other parents with children with special needs. 
All instruction took place in the NICU and PICU at James Whitcomb Riley Hospital for Children (Riley) in Indianapolis. Riley is Indiana's only comprehensive children's hospital and is committed to programs that address healthcare disparities. They have a 60 bed Level IV NICU which serves the diverse population of the Indianapolis and its surrounding communities. All modules were delivered bedside or in a family room near the room of the hospitalized infant. As the setting was the NICU or PICU, priorities were always placed on the medical care of the infants. Instruction was secondary, and was subject to the regular activities and procedures that commonly occur in such settings during scheduled instruction with parents. The research protocol was approved by the Indiana University Institutional Review Board (IRB) (see the attached document for the IRB approval).

Participants of this study were five (5) Latino caregivers of children who were admitted to the NICU or the PICU at Riley Children's Hospital in Indianapolis, Indiana during the six-month period from October 2015 to March 2016. Criteria for this study stipulated that participants had limited English proficiency (LEP), but were literate in Spanish, were 18 years of age or older and had a child that was expected to be hospitalized for at least three-weeks and was in stable condition. Healthcare professionals at Riley Children's hospital identified potential participants and referred them to ICIC and FVI. None of the referring professionals were co-investigators in this study and all participation was voluntary on the part of the participant. Participation was incentivized by the earning of gift cards for completing different stages of the study.

Intervention for each participant was completed in three-weeks or less. Instruction for three of the participants was done in the hospital room with their child present. The other two participants received instruction in a family room nearby. Prior to participating in the interventions, each participant was given a S-TOFHLA test in Spanish to measure his/her healthcare literacy and the Best PLUS test to measure his/her spoken English proficiency. Both tests were administered again after the interventions to measure changes in health literacy and spoken English proficiency.

To measure the efficacy of the developed six modules, researchers selected measurement tools representing diagnosed areas of concern. These include healthcare literacy, oral language proficiency and confidence to use English with the healthcare team. Data was collected using pre-tests, post-tests, observational notes and three follow-up phone interviews conducted 2, 4, and 6 weeks after completion of the interventions.

\subsection{Intervention}

\subsubsection{Needs Analysis}

As part of the requirements of an ESP approach, significant time was invested in needs assessment prior to development of the intervention modules. The needs of the NICU and PICU families were collaboratively identified working with stakeholders over a five-month period. A mini-ethnography was conducted, in which a researcher immersed herself into the NICU setting and collected information about the kinds of discourse that are used and how families interact with the nurses and other NICU and PICU staff. The researcher was fully bilingual in English and Spanish enabling her to observe interactions in both languages. Based on the results of the needs analysis, the materials to be used in the modules were created.

The needs analysis process included four different types of analysis: 1) target situation analysis; 2) present situation analysis; 3) learner factor analysis; and 4) teaching context analysis (Basturkmen, 2012).

1. Target situation analysis: We identified the language that the learners needed to communicate in the NICU context. We conducted a mini ethnography of the NICU, a focus group with NICU nurses and other key healthcare professionals, and an analysis of collected written materials. Data collected provided the context to ensure that the modules were designed with the specific needs of the families targeted in the study.

Dr. Diane Lorant, a neonatologist, informed the content of the teaching modules, and collaborated on the development of the materials and lesson plans. Other healthcare professionals, such as the NICU nurses were observed in the needs analysis as they initiated conversations with the participating families and made notes for our use in the ongoing assessment of the program and the participants. This analysis of language and NICU healthcare specialists contributed positively to the effectiveness of the instruction and informed the creation of the intervention modules.

2. Present situation analysis: We assessed the English proficiency levels of participants using the BEST PLUS test, and measured health literacy levels using the Spanish language version of the Short Test of Functional Health Literacy in Adults (S-TOFHLA). The information obtained from these tests showed where the participants were in relation to the demands of the communication skills they needed to develop. These analyses were conducted on each of the five participants of the pilot study prior to their participation in the interventions.

3. Learner factor analysis: The analysis was ongoing during the intervention, where the teacher communicated with the families to find out more about their motivations, needs, and wants in relation to learning English to communicate with healthcare professionals about their infant during the NICU stay and after discharge. 
4. Teaching context analysis: The researchers took into account the physical setting of the NICU when developing the modules, the amount of time the families could devote to the classes, issues related to possible health crises, and other environmental factors that could affect teaching and learning. Teaching context analysis took place in the initial needs analysis to inform the creation of the intervention modules and throughout the pilot study.

\subsubsection{Development of Modules}

The modules were produced over a two-month period. Data collected during the needs analysis found six items to be the most critical for parents to take a more active part in the healthcare teams of their children. Items of concern were parent rights and responsibilities, conveying personal information (numbers and spelling), scheduling and rescheduling appointments, reporting symptoms, reading medicine labels and dosing instructions, reading prescription labels, and talking with a pharmacist (Table 1).

Table 1. Summary of the six modules

\begin{tabular}{ll}
\hline Module \# & Content and Language Goals \\
\hline 1 & $\begin{array}{l}\text { Participants learn about their rights and responsibilities as caregiver members of a } \\
\text { healthcare team. No language goal is set as this module is conducted in Spanish. }\end{array}$ \\
2 & $\begin{array}{l}\text { Participants learn to interact with healthcare providers by giving personal information. } \\
\text { Numbers and spelling are taught in the context of providing personal information. }\end{array}$ \\
3 & $\begin{array}{l}\text { Participants learn to schedule and reschedule appointments and arrange transportation. } \\
\text { Language related to time and day are learned and used. }\end{array}$ \\
4 & $\begin{array}{l}\text { Participants learn how to report symptoms to their healthcare team. Symptom } \\
\text { vocabulary is practiced in the context of reporting concerns. }\end{array}$ \\
5 & $\begin{array}{l}\text { Participants learn to read medicine and prescription labels and apply appropriate dosing. } \\
\text { Measurement vocabulary is taught along with medicine and prescription label literacy. }\end{array}$ \\
6 & $\begin{array}{l}\text { Participants learn to interact with a pharmacist and read formula labels. Asking questions } \\
\text { to a pharmacist is practiced along with formula label literacy. }\end{array}$ \\
\hline
\end{tabular}

Following the ESP approach with a focus on intercultural communication, language, culture and skills were matched with the items of concern that emerged from the needs assessment (Figure 1). The language was tailored to the authentic samples of language used at the hospital to create dialogues that simulated commonly used vocabulary and structures from the NICU setting.

Modules were designed to take from 1 to 2 hours for completion. The first module, which covered parent rights and responsibilities, was taught completely in Spanish as the focus was not communicating but understanding the parental role within the healthcare team. The following five modules were conducted completely in English with targeted language structures that were reinforced with frequent repetition and dialogue-based practice to meet functional objectives. Activities were scaffolded by providing heavily scripted role-plays to begin lessons and preparing students to perform the function of the healthcare scenario without script by the end of each module. LEP parents performed scripted role-plays with the instructor, reviewed healthcare specific vocabulary through a variety of activities, and practiced the use of the vocabulary and targeted language structures. Each module had a pre-test and a post-test to measure progress towards functional objective completion. The pre-tests were comprised of questions made to participants to evaluate their ability to meet the content and language goals of the module. The post-tests were similar questions to evaluate participant progress towards meeting the goals. 
Figure 1. Module Sample

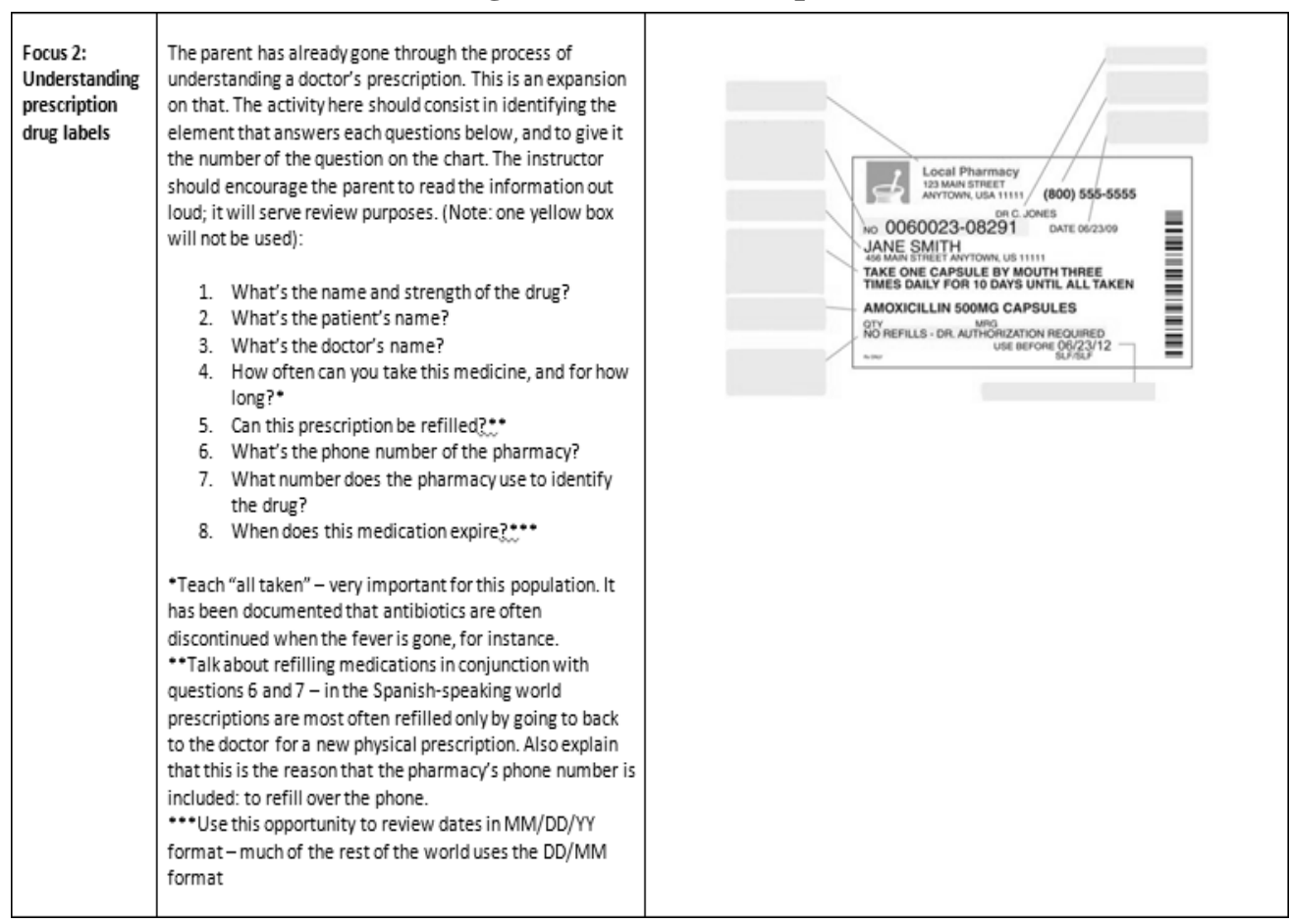

\subsection{Results}

\subsubsection{S-TOFHLA \& BEST Plus}

The S-TOFHLA is a cloze test with a score range of $0-36$ points with one point allotted for each cloze item. Participants had an average pre-test score of 30.7 with an average post-test score of 33.3. On average, participants test scores increased by 2.6. All participants showed improved health literacy scores from pre-test to post-test. Scores on the pre-test ranged from 27 to 33 while scores on the post-test ranged from 31 to 35 .

Best Plus has a score range from 0-162 and places students into proficiency levels from 0-10. Participants in this study averaged a score of 43 on their pre-tests and a score of 56 on their post-tests. The average improvement for participants was 13. All participants showed an increase in oral English language proficiency from pre-test to post-test.

\subsubsection{Module Specific Pre-and-Post Tests}

Each of the six modules had a pre-test and a post-test to measure functional objective completion. Participants were tested using module-specific communicative tasks to evaluate existing and learned skills using an internally-developed holistic scoring rubric. Participants were evaluated using a point system from 0-2. 2 points were awarded if the participant could answer the question correctly using the essential language. 0 was awarded if they were not able to answer the question correctly and 1 was given for those that answered partially or with a high degree of disfluency Each participant demonstrated progress towards objective completion in each module as all post-tests showed improved scores or remained the same as the pre-test scores. No scores decreased. All test score evaluations demonstrate that the tailored interventions were effective to improve participants' health literacy and oral language proficiency.

\subsubsection{Observational Journals}

Interactions with parents in the NICU and PICU were positive. Beginning the interventions with a native Spanish speaker from FVI and a bilingual instructor from ICIC helped set the parents at ease and served to build a relationship between FVI, ICIC and the parents. With relationships built, parents voiced their desire to learn English through participation in the interventions. Although instruction in the hospital room provided challenges, parents responded positively to the interventions. Classes required some flexibility on the part of the instructor and the parent. Nurses would enter the room to administer to the baby and doctors would occasionally enter to speak with the parent. There was noise from machines and occasionally from fussy babies. However, with only two instances of having to stop the class and return at a better time, parents were able to focus on the lessons provided and participate fully. Only on occasions where the parent received bad news from a doctor did any parent appear not to be in a proper emotional state to receive instruction. 
Although interventions were designed to instruct one caregiver, all participants shared materials friends or family members. Copies of materials were provided to the instructor and parent. Materials were left with the participant after the intervention was complete. Two participants took them home to work with their husbands, who also wanted to learn the content. Two participants reviewed them with their brother or wife and one participant reviewed them with her oldest son, who was fluent in English. This illustrates not only their desire to learn the content and initiative to go beyond the instructional sessions, but also the potential impact of the modules for other members of their children's healthcare teams.

Providing instruction to parents in the NICU or PICU did present unique challenges. Due to demands on the participants' time, it was necessary for instructors to be available to teach at hours that were most convenient to the parent. Classes were taught evenings, weekends, and holidays, in addition to regular working hours. Classes were often cancelled with little or no notice. There were instances of classes being cancelled, or postponed after the instructor arrived at the hospital due to unanticipated procedures or tests. A class was also rescheduled because of bad news delivered to a parent during a class session. The scheduling coupled with frequent interruptions or distractions presented challenges to the intervention process.

\subsubsection{Three Phone Interviews}

Follow up phone interviews highlighted the effectiveness of the modules for building confidence to take an active part in the healthcare team. Participants had varied situations during the six weeks after the interventions. Only one was discharged during that time period, but regardless of the situation, the phone interviews showed increased confidence and ability to interact with the healthcare team. All quotes are translated from Spanish, which was used to conduct all phone interviews (see appendix for a sample set of questions for the three phone call interviews).

The participant whose child was discharged stated the following: "Two weeks after I left the hospital, a nurse came to my house for a follow up home visit and she gave me some recommendations. She does not speak Spanish, but we were able to communicate with each other in English well. I am confident in English." She referenced this nurse multiple times during the three phone interviews and all comments were very positive. During the second interview she said, "I did not need an interpreter. I am very confident in my ability to communicate with her." The nurse did not speak any Spanish, but this parent felt confident in her ability to communicate using English. During the third phone call, she got more specific. "I had no problem explaining to her about the symptoms that my daughter had at home." This specifically addressed the ability to explain symptoms, which was one of the topics emphasized in the modules. Further examples of module related English were illustrated later in the conversation. "We talked about the formula, health condition, weight and progress as well." Formula, health condition and weight were all prominently featured in the modules.

Interestingly, this confidence and ability was not as high when talking with her doctor. "I spoke with the doctor 50/50 (English/Spanish). I was able to ask some questions but I needed the interpreter when the doctor explained to me the test results. I used the interpreter because I wanted to make sure that I understood everything right." From her comments, this use of the interpreter appears to only occur with her pediatrician. In her final phone interview, she mentioned this doctor again and said that she used English 50\% of the time and also used an interpreter. However, when visiting a pulmonologist she said, "I spoke with the doctor in English. There was not an interpreter in this appointment." From her answers, it appears that if given the chance to use an interpreter, she uses one to verify that she understands the doctor's instructions, but that she is able to communicate with doctors without interpreters if none are present.

We received similarly positive results from the parents that remained in the hospital after the interventions. The participant that began the program with the lowest proficiency scores reported in multiple calls that she is able to understand about $50 \%$ of discussions and speak with medical staff about $45-50 \%$ of the time. She still relies on the interpreter, but is confident to ask questions when the interpreter is not present. She feels she is able to communicate, but still needs an interpreter to make sure she understands what the medical personnel are telling her.

All participants mentioned that they were using English to communicate with nurses. Topics they reported discussing were: child's weight, bathing the child, blood sugar levels, changes in fluids, child temperature, medications and feeding. Of those topics, child's weight, temperature, medications and feeding were covered during the interventions. These reported topics positively support the development of modules around the items of concern which were identified in the needs analysis. 


\subsection{Discussion}

A six-module tailored English program was created for Latino parents of children in the NICU or PICU and delivered to five participants. These interventions were provided to parents while their children were hospitalized and delivered in the same room as the child or nearby by FVI and ICIC. Pre/post test scores showed positive improvement of parent health literacy in Spanish and English oral language proficiency. Follow up interviews provided qualitative data to show that participants used their English to participate confidently in their children's healthcare teams. Observational data showed that providing instruction in the NICU or PICU was effective, but also posed challenges with interruptions, affect awareness, and logistics.

This project was successful in developing a six-module program to meet the needs of Latino families with limited English proficiency with children in the NICU or PICU. Miquel-Verges, Donohue, \& Boss's study (2011) showed that after discharge from the NICU, Latino families had deficits in their knowledge about their infant's medical condition making it more likely for parents to seek emergency care and making vulnerable infants at further risk. This program shows potential to address concerns of Latino parent communication with healthcare teams prior to discharge from the NICU, thus improving parent knowledge of their infants' medical conditions. As taught, these modules are effective to improve the health literacy, oral English language use, and confidence of Latino parents to communicate with their healthcare teams, however, one obstacle remains. How can this program be reproduced in a way that maintains its effectiveness while being provided in a more feasible instructional model for the instructor?

While there is value in providing this program to parents in the hospital prior to discharge, it may be difficult for providers to accommodate the diverse scheduling needs of parents while exhibiting the necessary flexibility to handle cancelled classes and classes that are cut short. Therefore, the exploration of alternative models of instruction is encouraged. To maintain instruction prior to discharge, it may be more feasible to implement the use of technology to alleviate the travel to the hospital at odd times. Exploration of teaching short, tailored modules via web conferencing tools in the hospital setting should be investigated.

Further investigation of teaching these modules in an ESL classroom setting outside the hospital should be further explored. As this is a common practice for English for healthcare programs (Santos, Handley, Omark, \& Schillinger, 2014), further exploration is encouraged to determine if these same modules taught in an ESL setting would provide the same results in test scores and interview response. As these six-modules were designed for Spanish speaking healthcare providers of children in the NICU and PICU, it also merits additional exploration to expand the instruction to healthcare providers of people of all ages, language backgrounds, and conditions. This project was supported by the Indiana Clinical and Translational Sciences Institute (CTSI), funded by grant \#TR001107 from the National Institutes of Health National Center for Advancing Translational Sciences.

\section{References}

Andrulis, D.P., \& Brach, C. (2007). Integrating literacy, culture, and language to improve health care quality for diverse populations. Journal of Health Behavior. 31(1), 122-133 DOI:10.5555/ajhb.2007.31.

Basturkmen, H. (2012). Review of research into the correspondence between language teachers' stated beliefs and practices. System, 40, 282-295

Belcher, D. (Ed.)(2009). English for specific purposes in theory and practice. Ann Arbor, University of Michigan Press ELT.

Betz, C.L., Ruccione, K., Meeske, K., Smith, K., \& Chang, N. (2008). Health literacy: a pediatric nursing concern. Pediatric Nursing, 34(3), 231-239.

Byram, M. (1997). Teaching and assessing intercultural communicative competence. Clevedon, UK: Multilingual Matters.

Craig, J. (2016). The neonatal intensive care unit (NICU): Self-efficacy of caregiving and the lived experience of parents post-NICU discharge. Dissertation Abstracts International: Section B: The Sciences and Engineering, $76(12-\mathrm{B}(\mathrm{E}))$

Dudley-Evans, T, \& St. John, MJ. (1998). Developments in English for specific purposes: a multi-disciplinary approach. Cambridge: Cambridge University Press

Flores, G., Abreu, M., \& Tomany-Korman, S. (2005). Limited English proficiency, primary language at home, and disparities in children's health care: how language barriers are measured matters. Public Health Reports, Jul.Aug., 418-430

Institute of Medicine Committee (2002). Speaking of health: Assessing health communication strategies for diverse populations. Washington, DC: The National Academies Press. doi:https://doi.org/10.17226/10018. 
Jacobs, E., Lauderdale, D., Meltzer, D., Shorey, J., Levinson, W., \& Thisted, R. (2001). Impact of interpreter services on delivery of health care to limited-English-proficient patients. Journal of General Internal Medicine, 16(7), 468-474 DOI: 10.1046/j.1525-1497.2001.016007468.x

Karliner, L., Auerbach, A., Napoles, A., Schillinger, D., Nickleach, D., \& Perez-Stable, E. (2012). Language barriers and understanding of hospital discharge instructions. Med Care, 50(4), 283-289. doi:10.1097/MLR.0b013e318249c949

Litt, J. S., \& Perrin, J. M. (2014). Influence of clinical and sociodemographic characteristics on early intervention enrollment after NICU discharge. Journal of Early Intervention, 36(1), 37-48. doi:10.1177/1053815114555575

Lorant D. (2012). "Latino caregivers in the NICU". Unpublished survey, Eskenazi Health, Indianapolis, IN.

Mas, F.S., Mein, E., Fuentes, B., Thatcher, B., \& Balcazar, H. (2013). Integrating health literacy and ESL: an interdisciplinary curriculum for Hispanic immigrants. Health Promotion Practice, 14(2), 263-273. doi:10.1177/1524839912452736.

Miles, M. S., Carlson, J., Funk, S. G. (1996). Sources of support reported by mothers and fathers of infants hospitalized in a neonatal intensive care unit. Neonatal Network, 15(3), 45-52.

Miquel-Verges, F., Donohue, P., \& Boss, R. (2011). Discharge of infants from NICU to Latino families with limited English proficiency. Journal of Immigrant Minority Health, 13, 309-314.

Santarelli G. E., Denney M. K., Singer J., Singer G. H. S. (2000). "With my eyes I was telling her no": The experiences of fifteen Latino families in an NICU. Unpublished manuscript, University of California, Santa Barbara, CA.

Santos, M., Handley, M., Omark, K., \& Schillinger, D. (2014). ESL participation as a mechanism for advancing health literacy in immigrant communities. Journal of Health Communication, 19(2), 89-105.

Seideman, R. Y., Watson M. A., Corff, K. E., Odle, P., Haase, J., Bowerman, J. L. (1997). Parent stress and coping in NICU and PICU. Journal of Pediatric Nursing, 12(3), 169-177.

Singleton K. (2004). Picture stories for adult ESL health literacy. Online. Retrieved from http://www.cal.org/caela/esl_resources/Health/ (accessed 19 October, 2015).

Sneath, N. (2009). Discharge teaching in the NICU: Are parents prepared? An integrative review of parents' perceptions. Neonatal Network, 28(4), 237-238, 239-246.

Upton, T., \&Connor, U. (Eds.) (2013). Languagefor specific purposes section, The encyclopedia ofapplied Linguistics. New York: John Wiley and Sons

Zarcadoolas, C, Pleasant, A, \& Greer, D. (2005). Understanding health literacy: an expanded model. Health Promotion International, 20(2), 195-203 DOI:10.1093/heapro/dah609

Appendix

1. Sample Set of Questions for Three Phone Call Interviews:

\begin{tabular}{|c|c|c|}
\hline $\begin{array}{l}\text { A. In the } \\
\text { past two weeks, } \\
\text { have you... }\end{array}$ & B. If YES, ask & C. If YES, rate the degree of success \\
\hline $\begin{array}{l}\text { Called } \\
\text { emergency, or the } \\
\text { doctor's office? }\end{array}$ & $\begin{array}{l}\text { - Why did you call? } \\
\text { - Did you communicate in English? }\end{array}$ & $\begin{array}{l}\text { Callers should } \\
\text { (A) ask whether parents engaged in this kind of } \\
\text { communication in the real world for the first time, } \\
\text { and }\end{array}$ \\
\hline $\begin{array}{l}\text { Used public } \\
\text { transportation? }\end{array}$ & $\begin{array}{l}\text { - What kind? } \\
\text { - Did you plan your trip? How? } \\
\text { - Did you communicate with the bus } \\
\text { driver? }\end{array}$ & $\begin{array}{l}\text { (B) obtain enough information on the } \\
\text { communication event so that they can rate parents' } \\
\text { success on a } 2-1-0 \text { scale, where } \\
2=\text { successfully } \\
1=\text { part successfully } \\
0=\text { unsuccessfully; an interpreter was needed, or } \\
\text { the attempt ended in failure to communicate }\end{array}$ \\
\hline
\end{tabular}




\begin{tabular}{|c|c|c|}
\hline $\begin{array}{l}\text { Taken your child } \\
\text { the doctor? }\end{array}$ & $\begin{array}{l}\text { - Why did you take him/her? } \\
\text { - Did you communicate in English? } \\
\text { Did you fill out a form while at the } \\
\text { doctor? } \\
\text { - Did you tell the doctor about your } \\
\text { child's progress/problem? } \\
\text { - Did you ask for health information } \\
\text { from your doctor? } \\
\text { Did you understand what the doctor } \\
\text { said to you? } \\
\text { Did you schedule a follow-up } \\
\text { appointment? }\end{array}$ & \\
\hline $\begin{array}{l}\text { Filled a } \\
\text { prescription at the } \\
\text { pharmacy? }\end{array}$ & $\begin{array}{l}\text { - Did you communicate in English? } \\
\text { - Did you understand the pharmacist? } \\
\text { - Did you ask any questions of the } \\
\text { pharmacist? }\end{array}$ & \multirow{3}{*}{$\begin{array}{l}\text { D. Are you ready for more? } \\
\text { A question to end the third call should involve } \\
\text { readiness, i.e. continuing English instruction in } \\
\text { the community. "Are you planning to register for } \\
\text { classes? Have you started Where? What kind?" The } \\
\text { parent may be very busy with life at the moment, } \\
\text { but detail in the answers would convey readiness, } \\
\text { which is what we want going on record. }\end{array}$} \\
\hline $\begin{array}{l}\text { Read health } \\
\text { information? }\end{array}$ & $\begin{array}{l}\text { - Printed or online? } \\
\text { - What kind? Prescriptions? Medication } \\
\text { labels? }\end{array}$ & \\
\hline $\begin{array}{l}\text { Used English in } \\
\text { any other way? }\end{array}$ & $\begin{array}{l}\text { - Where? Who did you communicate } \\
\text { with? Explain. }\end{array}$ & \\
\hline
\end{tabular}

\begin{tabular}{|c|c|c|}
\hline $\begin{array}{l}\text { A. En estas dos } \\
\text { semanas, usted... }\end{array}$ & B. Si la respuesta es SÍ, pregunte & $\begin{array}{l}\text { C. Si la respuesta es } \\
\text { Sí, evalúe } \\
\text { efectividad la } \\
\text { comunicación }\end{array}$ \\
\hline $\begin{array}{l}\text { ¿Llamó a emergencias } \\
\text { o a la oficina del } \\
\text { doctor? }\end{array}$ & $\begin{array}{l}\text { - ¿Por qué llamó? } \\
\text { - ¿Se comunicó en inglés? }\end{array}$ & \multirow{3}{*}{$\begin{array}{l}\text { La persona que llame } \\
\text { debe } \\
\text { (A) Preguntar al } \\
\text { padre/a la madre si fue } \\
\text { la primera vez que se } \\
\text { comunicó en inglés con } \\
\text { este fin en la vida real } \\
\text { (es decir, fuera de la } \\
\text { clase) y } \\
\text { (B) Obtener } \\
\text { información que permita } \\
\text { evaluar la efectividad de } \\
\text { la comunicación según } \\
\text { esta escala: } \\
2=\text { No tuvo problemas } \\
\text { en comunicarse } \\
1 \quad=\text { Tuvo alguna }\end{array}$} \\
\hline $\begin{array}{l}\text { ¿Usó el transporte } \\
\text { público? }\end{array}$ & $\begin{array}{l}\text { - ¿De qué tipo? } \\
\text { - ¿Hizo un plan de viaje por anticipado? } \\
\text { - ¿Se comunicó con el conductor? }\end{array}$ & \\
\hline $\begin{array}{l}\text { ¿Llevó a su hijo/a a la } \\
\text { consulta con el } \\
\text { médico? }\end{array}$ & $\begin{array}{l}\text { - ¿Por qué lo/la llevó? } \\
\text { - ¿Se comunicó en inglés? } \\
\text { - ¿Llenó un formulario en la sala de espera? } \\
\text { - ¿Le dijo al doctor acerca del progreso de su bebé, o } \\
\text { acerca de algún problema? }\end{array}$ & \\
\hline
\end{tabular}




\begin{tabular}{|c|c|c|}
\hline & $\begin{array}{l}\text { - ¿Le hizo preguntas al doctor? } \\
\text { - ¿Entendió lo que el doctor le dijo? } \\
\text { - ¿Hizo una nueva cita? }\end{array}$ & $\begin{array}{l}\text { dificultad; la efectividad } \\
\text { fue parcial } \\
0 \quad \text { No pudo } \\
\text { comunicarse; necesitó la } \\
\text { asistencia de un } \\
\text { intérprete o fracasó en el } \\
\text { intento }\end{array}$ \\
\hline $\begin{array}{l}\text { ¿Compró } \\
\text { medicamentos en la } \\
\text { farmacia? }\end{array}$ & $\begin{array}{l}\text { - ¿Se comunicó en inglés? } \\
\text { - ¿Entendió al farmacéutico? } \\
\text { - ¿Le hizo preguntas al farmacéutico? }\end{array}$ & $\begin{array}{l}\text { D. ¿Quiere saber } \\
\text { más inglés? } \\
\text { La tercera llamada debe } \\
\text { concluir con una } \\
\text { pregunta acerca de las }\end{array}$ \\
\hline $\begin{array}{l}\text { ¿Leyó alguna } \\
\text { información médica? }\end{array}$ & $\begin{array}{l}\text { - ¿En papel o en línea? } \\
\text { ¿Información de qué tipo? ¿La receta del doctor? } \\
\text { ¿Información acerca de la medicación que viene en la } \\
\text { caja? }\end{array}$ & $\begin{array}{l}\text { tomar clases de inglés } \\
\text { en su comunidad. Es } \\
\text { probable que el bebé } \\
\text { ocupe la mayor parte de }\end{array}$ \\
\hline $\begin{array}{l}\text { ¿Habló en inglés por } \\
\text { algún otro motivo? }\end{array}$ & - ¿Dónde? ¿Con quién se comunicó? Describa la situación & $\begin{array}{l}\text { momento. Pero si el } \\
\text { padre/la madre provee } \\
\text { información específica } \\
\text { (donde va a tomar clases } \\
\text { y cuando piensa } \\
\text { comenzar, por ejemplo), } \\
\text { esto constituye } \\
\text { intenciones claras y } \\
\text { debe consignarse. }\end{array}$ \\
\hline
\end{tabular}

